\title{
Grading in Portuguese secondary school physical education: assessment parameters, gender differences and associations with academic achievement
}

José Marmeleira, Hugo Folgado, Ismael Martínez Guardado \& Nuno Batalha

To cite this article: José Marmeleira, Hugo Folgado, Ismael Martínez Guardado \& Nuno Batalha (2019): Grading in Portuguese secondary school physical education: assessment parameters, gender differences and associations with academic achievement, Physical Education and Sport Pedagogy

To link to this article: https://doi.org/10.1080/17408989.2019.1692807

Published online: 19 Nov 2019.

Submit your article to this journal $\pi$

Q View related articles $\sqsubset$

View Crossmark data $ऍ$ 


\title{
Grading in Portuguese secondary school physical education: assessment parameters, gender differences and associations with academic achievement
}

\author{
José Marmeleira (D) ${ }^{\mathrm{a}, \mathrm{b}}$, Hugo Folgado (D) ${ }^{\mathrm{a}, \mathrm{b}}$, Ismael Martínez Guardado (1) ${ }^{\mathrm{c}}$ and \\ Nuno Batalha (iD) a,b \\ aDDepartamento de Desporto e Saúde, Escola de Ciências e Tecnologia, Universidade de Évora, Évora, Portugal;

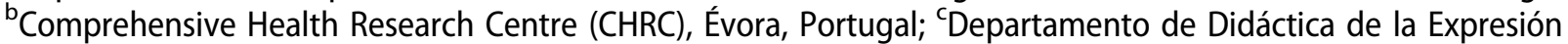 \\ Musical, Plástica y Corporal, Facultad de Ciencias del Deporte de Cáceres, Universidad de Extremadura, Cáceres, \\ España
}

\begin{abstract}
Background: Assessment is crucial for the quality of teaching and learning in physical education (PE). Currently little is known about the students' level of achievement in PE and about the parameters used for calculating the PE grades. Although there is evidence that boys are more active outside school than girls and participate more in organized sports, few studies have examined possible differences between genders in PE achievement. Furthermore, despite the current interest in the relationship between motor competencies and cognitive functioning, limited research has examined if PE grades are associated with academic achievement.
\end{abstract}

Purpose: Considering the lack of information on the current level of students' success in PE, the main aim of this study is to examine the PE grades of Portuguese students in secondary school. Specifically, this study analysis the level of students' achievement in PE, the relation of PE grades with other school subjects' grades, compares the PE grades between boys and girls, and presents the PE summative assessment parameters used in schools.

Method: Participants were 1936 students (57\% girls) from the 10th, 11 th and 12th grades (16.8 \pm 1.3 years old) attending eleven Portuguese secondary schools. Information was gathered on their grades in PE and in the other school subjects at the end of the school year. Information on the specific assessment parameters used in each school was also collected.

Results: The average grades in PE were $14.9 \pm 2.3$ points (20-point scale). Only $\sim 1 \%$ of students with a final PE grade had a negative performance $(<10$ points). PE grades were relatively higher than in most of the other school-subjects and for most students (68.7\%) the PE classification raised their overall average grade. The level of correlation between grades in $\mathrm{PE}$ and in other school subjects was statistically significant $(r ' s=.13$ to $.29, p<.05)$ although lower than that between grades in the other school subjects $\left(r^{\prime} s=.44\right.$ to $\left..84, p<.01\right)$. There were significant differences between girls' and boys' grades in PE $(14.3 \pm 2.3$ and $15.9 \pm$ 2.1 points, respectively). The school assessment parameters prioritize physical performance over participation and attitude.

\section{ARTICLE HISTORY}

Received 4 June 2018

Accepted 7 November 2019

\section{KEYWORDS}

Assessment; physical education; students' achievement; high school 
Conclusion: The Portuguese students' level of achievement in PE seems to be very satisfactory. However, as boys have higher grades than girls it is urgent to find appropriate strategies to tackle this problem. The associations found between PE grades and academic achievement could have relevant repercussions considering the current debate about the status of PE and about the relationship between motor and cognitive competencies. It is also relevant that the schools' summative assessment parameters are based mainly on skill mastery and not on effort and participation. This study provided a brief glance into some aspects of the assessment of PE in Portugal and is it is desirable that future investigations examine the teacher's assessment practices.

\section{Introduction}

Assessment is a crucial aspect for the quality of teaching and learning in physical education (PE) (Collier 2011; Borghouts, Slingerland, and Haerens 2017). Among others, it gives feedback about the students' learning progress and on the effectiveness of teaching methods and PE curriculum. Often, assessment is accompanied by actions for reducing or closing the gap between the students' performance and the learning goals. The formative and summative assessment provides important information to the $\mathrm{PE}$ teacher, enabling the promotion of more adequate strategies for supporting students' learning process, taping relevant aspects like confidence, motivation and learning potential (Stiggins 2007; Borghouts, Slingerland, and Haerens 2017). From a psychosocial point of view, the summative assessment type is probably the most noticeable form of academic evaluation as it is used for students' certification and classification, having a direct impact in the students' and families' lives. Nevertheless, its value is way beyond students' certification and classification.

In recent years some negative feelings toward summative assessment have emerged in the educational literature. In the effort to promote assessment for learning, education literature is creating a potential harmful dichotomy between summative and formative assessment, generally pointing the former as 'bad' assessment and the latter as 'good' assessment (Lau 2016). It is symptomatic that although the subject of assessment in PE has been receiving attention in the international research literature (Collier 2011; Aune et al. 2017), most studies focused in formative assessment and few reported information on PE summative assessment, especially on grading.

The summative assessment does not have to be an 'end in itself and is closely connected with the formative form of assessment. Lau (2016) highlights that summative and formative assessment are connected at their inception, and according to Taras (2005) it is not possible for assessment to be uniquely formative without the summative judgment having precede; summative assessment could and should also support learning when used for feedback. What is meaningful is not the 'name' but the function of assessment, since the same assessment results can be used in different ways (Harlen 2012). In this perspective, it is wrong to think that summative assessment is only about the assessment of learning. If properly used it is also about assessment for learning.

At the school level, the students' assessment in each PE content is helpful by providing feedback to students (and teachers) on their current level of achievement, and should be considered for adjusting learning goals, learning activities and inform other pedagogical decisions (e.g. instructional and curricular models). According to Newton (2007) the aggregation of the grades achieved by the students can be useful to: Identify needs and, consequently, provide a basis for allocating resources; identify failure and, consequently, provide a basis for justifying intervention; evaluate the success of educational programmes or initiatives (nationally or locally); and to decide whether system standards are rising or falling over time. Thus, at the level of the educational system, summative assessment results provide important information for programme and policy-making. As Sundaresan, 
Dashoush, and Shangraw $(2017,36)$ recently pointed out it is imperative that physical education be supported by assessment-driven evidence in order to reach and speak to legislators, national boards, school administrators, educators and the students themselves.'

The current article is focused on grading in PE, a facet of summative assessment for which there is a lack of information in Portugal. In this context, this study is focused on a number of relevant aspects about PE grades of Portuguese students in secondary school, including the relationship of $\mathrm{PE}$ grades to other school subjects' grades, the possible differences in PE grades between boys and girls, and the PE summative assessment parameters currently being used in schools. We hope to provide information that can help set the basis for future in-depth examinations into the PE assessment process in the country. One should note that, although there is no consensus in the educational literature, in the present study we follow the conceptual clarification of Rasberry et al. (2011). These authors view academic performance as a broad concept encompassing several factors that may influence students' success in school, including cognitive skills and attitudes, academic behaviours, and academic achievement. In particular, academic achievement includes elements like standardized test scores, classroom tests, or school grades, being the latter the main focus of the current study.

For supporting a clear view on the current knowledge and discussion around the assessment dimension in PE, we revise in the next sections a number of relevant aspects, including the importance of a quality grading in PE, and the relationship between PE, gender and academic performance. We also describe the main features of the Portuguese PE programme, which is the primary reference for the curricular organization of PE and assures a reasonable level of standardization of PE contents, learning goals and assessment practices across Portuguese schools.

\section{Quality grading in PE and PE status}

It is frequently recognized that $\mathrm{PE}$ is devalued within the educational system, involving facets as the beliefs of students and teachers, the parents and social perceptions, the organization of the school curriculum and the value it attributes to each curricular subject (Collier 2011; Richardson 2011; Penny 2013). Some reasons for such devaluation have been pointed in the literature, including poor pedagogical practices in the past, inadequate curriculum (Collier 2011; Sheehy 2011), and the generalized social perception that academic subjects dependent on cognitive abilities (e.g. mathematics and physical sciences) are more prestigious then others dependent on artistic, expressive, or bodily-athletic qualities (Bailey 2018). Most important for the current article, unadjusted assessment systems have been also pointed to compromise the PE status (e.g. Collier 2011; Sheehy 2011).

Fortunately, with the advent of standards-based PE the relevance of using gradings systems that informs and truly assesses learning has gained momentum (Melograno 2007). According to Melograno (2007), the criteria established for grading should communicate essential information to students, including what the teacher values and believes is important from them to learn, how students should focus their attention and effort, and how the criteria will be combined and weighted to determine grades. Most grading systems are structured by weighting the contribution of specific behaviours (e.g. motor performance, knowledge and attitudes) to computing the final grade.

Independently of the school's context, students should share the same opportunities for learning and assessment. Thus, independently of the specific pedagogic decisions that occur at the school and class levels, it seems desirable that common syllabus, learning goals and criterion assessment systems are established at the educational system level. In their article on the student views on assessment and grading in Swedish PE, Redelius and Hay (2012) concluded that the grading systems in PE should reflect the official goals or criteria upon which judgements will be made, should be collected through an ongoing process and should be accessible to both teachers and students prior to the final grading decision. The authors also highlight that students should be both aware of the criteria upon which decisions are made and have access to and understand how to respond to the information that has been collected on their performances. 
Melograno (2007) outlined a number of practical guidelines for quality grading in PE, including the importance of grading and standards to be directly aligned, of grading from clear descriptions of performance standards (i.e. grades should be the consequence of student's achievement rather on the comparison of their performance with the performance of other students), and of students be directed involved in assessment and grading. The author also highlights that aspects like attendance, dressing for class, effort, participation, and other learning and social behaviours, should be reported separately and not be included in the summative assessment. This latter aspect has been discussed with some frequency in the PE literature, and most authors agree that the significant valorization of such variables for calculating the students' grades is one major reason that has contributed historically to compromise the social status of PE (Baghurst 2014; Collier 2011; Sundaresan, Dashoush, and Shangraw 2017).

\section{Do PE grades mirror the differences between boys and girls found in other physical activity and sports contexts?}

One particular issue considered in this paper is the student's achievement in PE according to gender. The few studies that have examined this issue point that boys tend to have better results in PE summative assessment than girls, but girls get higher grades than boys in other school subjects (Ericsson and Cederberg 2015; Aune et al. 2017). It is known that there are differences between boys and girls in competencies and behaviours that are valued in PE assessment. For instance, the participation in physical activity and sports activities outside of school is more prevalent in boys than in girls, which could have an impact in the students' general motor competence and sports skills during the PE lessons. The high participation of boys in sports could be one of the primary reasons why they engage in higher levels of physical activity than girls, which in turn could raise their physical fitness levels, a subject that is also much considered in PE. A study in Iceland with a representative sample of 6th, 8th and 10th-grade students found that girls' lower participation in organized sports clubs was closely related with gender differences on the enrolment (quantity and intensity) in physical activity (Vilhjalmsson and Kristjansdottir 2003). Also, a recent longitudinal study in Australia reported that sports club participants (8-16 years, both genders) were more physically active and physically fitter than non-participants (Telford et al. 2016). In Portugal, boys are also more involved in organized sports than girls (51.3\% and $28.3 \%$, respectively) and those who engage in organized sports are more likely to achieve physical activity guidelines (Marques, Ekelund, and Sardinha 2016). In line with these findings, there is empirical evidence that children who consistently practice sports in a club environment display better coordination levels than children who did not practice sports (Vandorpe et al. 2012).

Physical education seems to mirror the differences between genders in physical activity outside the school, as there is some evidence that girls show lower levels of moderate to vigorous physical activity (MVPA) than boys during PE lessons (Smith, Lounsbery, and McKenzie 2014; Timo et al. 2016). This trend could be related with the fact that boys seem to enjoy and have more interest in $\mathrm{PE}$ lessons and perceived their competence in a more positive way than girls (Marmeleira, Aldeias, and Graça 2012; Fairclough 2003). It is important to highlight that, in general, boys have better motor skill competence and are more involved in sports than girls (Spessato et al. 2013; Hardy et al. 2012). Taken together, it could be that boys are in an advantageous position in PE assessment, as it typically values the performance in sports-related activities and physical fitness.

\section{On the relationship between PE and academic performance}

In recent years there has also been a growing interest in the relationship of $\mathrm{PE}$ with cognitive functioning and academic achievement. Such attention is probably a consequence of new evidence on the positive role of physical activity in brain and cognition (e.g. Marmeleira 2013; Hillman, Erickson, and Kramer 2008). Thus, as PE is the school subject most related with physical activity and physical 
fitness, it seems natural that recently some scientists have directed their interest to the role played by $\mathrm{PE}$ in cognitive functioning and academic performance (Donnelly et al. 2016; Rasberry et al. 2011). Also, the study about the relationship between PE and academic achievement could be related to an attempt of enhancing the PE status within an educational system, which, unfortunately, frequently overemphasizes intellectual competences. As a fact, some countries have reduced the amount of school PE with the argument that by giving extra time to 'academic' school subjects they could enhance students' performance (UNESCO 2014).

Several psychological and brain mechanisms have been proposed for mediating the impact of physical activity and physical fitness on cognition, including neuroplasticity, brain health, cerebral circulation, self-esteem, arousal and mood, and increased attention span and concentration (Hillman, Erickson, and Kramer 2008; Esteban-Cornejo et al. 2015; Coe et al. 2006). Ericsson (2008), showed that increasing PE (from 2 days per week to daily) in elementary school was associated positively with math, reading, and writing test scores, and Sallis et al. (1999) reported that an intensive 2year health-related PE programme had a generally positive impact on reading, language, and basic battery standardized test scores. Coe et al. (2006) found that enrolment in PE was not significantly related to academic performance in middle school children, but that the minutes they spent per day in vigorous physical activity were positively associated with higher grades. Another study that used data from a public examination taken by high school students in England, Wales and Northern Ireland at the end of compulsory schooling (age 16 years), reported a weak but positive correlation between academic ability (English and mathematics) and sports performance (Dexter 1999). In this case, it is important to note that PE was an optional subject and therefore it was more likely to be chosen by pupils who enjoyed sport.

Although some studies linked PE and academic performance, there is also a comparable number of studies that did not find any relationship (Rasberry et al. 2011). Measuring the contribution of PE to academic performance is a challenging and complex task due to the diversity of PE (e.g. content, instructional models, levels of physical activity, weekly frequency and duration). A study with adolescents reported that for PE having a significant impact in cognitive performance and academic achievement, it is necessary to have high-intensity PE lessons in almost all days of the week (Smith, Lounsbery, and McKenzie 2014). The reality is that mainstream PE is not particularly well succeed in engaging students in high levels of physical activity intensity in countries such as Portugal, Spain, and England, where MVPA values vary between $27 \%$ and $34.3 \%$ of the lesson time (Fairclough and Stratton 2005; Marmeleira 2013; Mayorga-Vega, MartínezBaena, and Viciana 2018).

\section{The Portuguese PE programme and its summative assessment norms}

In Portugal, PE is included in students' curricula in all school years, that is, from kindergarten to 12th grade. There are specific PE guidelines for kindergarten, and a specific PE curriculum for the Primary school (1st to 4th year) (Silva et al. 2016; Direção Geral da Educação, n.d.). For the 2nd (5th to 6th school years) and 3rd (7th to 9th school year) school cycles and for the secondary education (10th to 12th school year) the national PE programme are the main reference for the organization of $\mathrm{PE}$ in schools (Jacinto et al. 2001a, 2001b; Ministério da Educação 1998). They include the general learning goals of PE, the curriculum plan to be developed, identifies the resources needed for implementing the programme successfully and provides norms for assessment (Jacinto et al. 2001b).

In its general goals, the Portuguese PE programme highlights the promotion of motivated physical activity participation, health-related physical fitness, physical activity-related knowledge and of competencies as autonomy, responsibility, ethics and creativity. The PE curriculum has the general characteristics of a standards-based curriculum (please see MacPhail 2015), identifying the physical activity- and physical fitness- related skills and knowledge that students should acquire during their progression within the educational system. The standardization of PE learning goals tries to ensure that all students have the opportunity to experience comparable challenges and beneficiate from the 
high potential of development offered by the movement-based culture. The PE programme designates specific learning goals (physical-motor, technical-tactic, cooperation skills) to be achieved by the students in each physical activity, which become gradually more challenging as the students' progress to subsequent academic years and are grouped into three developmental levels for each content: initial, elementary and advanced. Physical activities are divided into 4 main areas, namely sports (team sports, gymnastics, athletics, racquet sports, combat sports and swimming), expressive movement activities (e.g. dance), traditional/popular games and nature-related physical activities (e.g. orienteering, climbing and canoeing). Some physical activities are core in the curriculum, and some are alternative (selected at the school level). Regarding specifically the secondary school, the 10th grade is mainly dedicated to the revision and consolidation of the physical activities practiced during the years of basic education. In the 11th and 12th grades, the number of physical activities is diminished, and it is proposed that the students choose six physical activities subjects (two from team sports, one from gymnastics or from athletics, dance and other two from the remaining) in each they would like to enhance their competence. In secondary education, schools provide 150 min (divided into periods of $50 \mathrm{~min}$ ) or $180 \mathrm{~min}$ (divided into periods of $45 \mathrm{~min}$ ) of PE per week. The national PE programme recommends that PE lessons should occur 4 days per week (45-min lessons).

The national PE programme highlights the importance of each teacher implementing in the first 5-6 weeks of the academic year an initial assessment of students' competencies in the several physical activities that compose the PE curriculum. In this period, using rating scales adjusted to the national PE programme contents, the teacher collects diverse information on the students strong and weak areas. This information supports pedagogical decisions related with the subsequent planning of the academic year, such as the choice of physical activities (and physical fitness components) to be prioritized and the estimation of the number of lessons to be dedicated to them, the adjustment of learning progressions or the formation of appropriate working groups of students. In the 11th and 12th grades, it is also expected that during the initial assessment, the students select some of the physical activities in which they want to develop their competencies during the school year.

Teachers are recommended to adopt annual PE plans for each class. Among other aspects, these plans include a number of schemes or units of work, with specific contents, learning objectives and instructional strategies. The classes can be polythematic and the number dedicated to each content is adjusted to the student's characteristics (more learning time is dedicated to contents where students are more distant from the learning goals). Students from the same class do not necessarily engage in the same activities during each lesson; such pedagogical decision is taken for assuring for each student (or group of students) the best pathway to success in PE. Thus, for a quality PE, the national programme assumes that students must know what is expected from them, what are the learning objectives that are established for them, and what is their distance to such objectives. These principles are in line with the idea of assessment for learning (Leirhaug and Annerstedt 2016). As for other similar standard-based curricula (MacPhail 2015), the Portuguese national PE programme seems sufficiently flexible for allowing schools and teacher to take into consideration the specific schools' and students' characteristics.

Regarding the students' assessment, in Portugal, as in other countries, a criterion-referenced system prevails in PE where students' skills are assessed in relation to goals or criteria developed before the student engagement in a learning unit (Redelius and Hay 2012). The PE programme includes assessment norms which state that physical activities, physical fitness and PE-related knowledge are the 3 main curriculum areas to be considered in the grading process. The competencies usually associated with the socio-affective domain, are not pointed out separately, as they are considered intertwined with the attainment of skills in the other domains. The student is graded in each physical activity subject (e.g. basketball, swimming) according to his/her performance, for which the PE programme considers three possible categories: (a) introductory level, (b) elementary level, (c) advanced level. In the secondary school, the grade in the physical activities area results from assessing six physical activity contents, which are selected from those where each student achieves the best 
performance (PE programme includes specific rules to assure that this selection is eclectic). To be successful in the physical activities area, the students should attain at least three introductory and three elementary levels. According to the national PE programme, the students are successful in secondary PE ( $\geq 10$ points) if they achieve success in the physical activities area, if they are in the healthy zone in physical fitness, and if they know the fundamental PE-related knowledge.

Finally, it is important to note that in recent years there has been some debate within the Portuguese educative community regarding the status of the PE grades. Thus, although for completing the secondary school, students must have success in all curricular school subjects, during the school years of 2012-2013 to 2017-2018 (therefore including the school year studied in this article) the PE grade was not considered as part of the secondary school aggregate grade used for the application to the higher level of education (except for higher education PE related courses). Recently, the Portuguese government reverted this decision, and the PE grade is again part of the aggregate grade used in the admission to all courses at higher education level.

\section{Research questions}

The main aim of this study is to examine the PE grades in Portuguese secondary schools. Specifically, we define a number of research questions:

- What is the current level of students' achievement in PE in Portugal?

- How are PE grades related to other school subjects' grades?

- Do boys and girls get similar PE grades in Portugal?

- What are the PE summative assessment parameters used in Portuguese schools?

\section{Method}

\section{Participants and design}

Thirty-five secondary schools from an extensive region of Portugal - Alentejo - were contacted by email and asked for their cooperation. The e-mail contextualized the study, described their main objectives and asked the schools boards to provide information about the grades achieved by each student in the final (third school period) summative assessment regarding the school year 2014-2015. Information on the students' grades was requested for all school subjects from the 10th, 11th, and 12th grades. For maintaining participants' anonymity, schools were asked to provide only information on the students' age, sex, and respective grades. Accordingly, in the data received from schools, in place of students' names there were codes (numbers) associated with the information on grades, sex and age. Students were included in the sample if they have at least a numeric grade in one school-subject (students that for some reason were not evaluated were excluded from the study).

Twelve schools agreed to participate and shared by e-mail the grades of their students. In the case of one school, it was not possible to identify to which student belonged each grade, and therefore the data was not considered. There were 1936 participants in total from eleven schools; one school (164 students) did not provide information on the students' gender, and in the remaining 1772 students, 1010 were girls and 762 were boys. There were 1734 students with a summative evaluation in PE. The average students' age was $16.8 \pm 1.3$ years and age amplitude was $14-21$ years. The study was conducted according to the Helsinki Declaration and approved by the Ethics Committee of the hosting university.

\section{School grades}

In Portugal, the school year is composed of three periods (approximately three months each), and the students receive a quantitative summative grade in all school subjects at the end of each school period, with the final grade being the classification received at the end of the third school period. In 
the current study, we use the grades relative to the third school period of the general education programmes. In the Portuguese secondary school system, the grade scale is from 0 (lowest) to 20 points (highest). Nine or fewer points in a school subject is considered as negative performance and it might prevent the student from enrolling in that subject in the subsequent school year. Also, depending on the number of school subjects with negative scores, the students might not progress to the following academic year, being retained and repeating the same year. In secondary schools, all programmes include PE and Portuguese language as mandatory subjects on the 10th, 11th, and 12th grades, and philosophy and one foreign language as mandatory subjects on the 10th and 11th grades. There is also a number of school subjects which varies according to the curricular programme (e.g. Sciences and Technologies, Social and Human Sciences) that the students choose when they enter the secondary school.

\section{Information on the schools' PE summative assessment parameters}

Although the national PE programme describes the criteria for considering that the student achieved success in PE, it does not specify how the final numeric grade is calculated. Thus, taking into consideration the general assessment norms provided by the national PE programme, each school defines their final summative assessment parameters, which are presented to students by their teachers at the beginning of the school year. Such information is also publicized in the schools' websites, from where it was collected for the current study. Where available, we also collect the general summative assessment parameters for other school subjects.

\section{Statistical analysis}

Due to the number of school subjects, some of them with a small number of students enrolled, we choose to report data for those in which more than 250 students had a summative grade. Also, when students had more than one foreign language in their curriculum, their mean grade was considered. As Biology and Geology appear as a single curricular school-subject more frequently than separately, we choose to always present them together after calculating their grade mean. For the same reason, an identical procedure was applied to Chemistry and Physics. An academic achievement score for each student was calculated by computing the average grade of all school subjects with and without PE.

Pearson correlations were applied to examine the associations between school grades. Correlation thresholds of 0.10, 0.30 and 0.50 represent small, moderate and high correlations respectively (Cohen 1987). Independent sample $t$-test was used to compare school grades between girls and boys. Participants were grouped according to their quartile of PE grade and one-way ANOVA with post-hoc Scheffe's test were conducted to determine if there were differences between the 4 subgroups in the overall students' average grade. Analyses were conducted with the statistical software SPSS Statistical for Windows (version 21.0; IBM SPSS Inc., Chicago, IL, USA). For all statistical tests, significance was set at $p<.05$.

\section{Results}

Table 1 shows the students' average grades by curricular subject and also their correlations. We found significant positive associations between grades of all curricular school subject. Although statistically significant, the association between the grades in PE and the grades in the other school subjects was small ( $r$ 's $=.13$ to .29 ). In accordance, the correlation between the PE grades and the average grade on the other school subjects was also small $(r=.23, p<.01)$. All other computed correlations between grades in the different school subjects were statistically significant at a moderate or high level ( $r$ 's $=.44$ to .84$)$. The mean classification in PE was $14.9( \pm 2.3)$ points, which was the second highest grade average from all school subjects (only Psychology, $15.5 \pm 2.3$ points, had a higher 


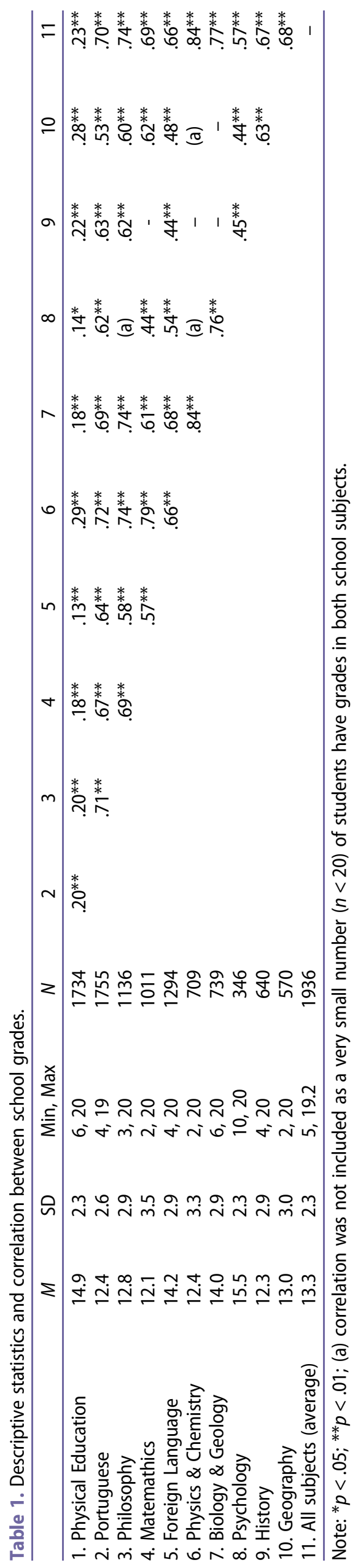


average grade, but only 346 students were enrolled). The overall students' average grade was $13.3 \pm$ 2.3 points including the PE grade and $13.0 \pm 2.5$ points without the PE grade.

For 1192 students (68.7\%), the grade in PE raises their overall school grade point average, and for the remaining 542 students $(31.3 \%)$ the PE grade reduced that score. From the 1734 students that had a final classification in PE, only $16(0.9 \%)$ had a grade inferior to 10 . As it can be seen in Figure 1, the students' overall grade increased incrementally across the quartile groups formed according to the PE grades. ANOVA results showed that there were significant differences in the students' overall grades between the PE quartile groups $\left(F_{3,1730}=27.1, p=.011\right)$. Post hoc tests showed that students from the quartile group 1 had lower average school grades (12.5 \pm 2.2 points) than students from quartile $2(13.1 \pm 2.3$ points, $p<.01)$, quartile $3(13.5 \pm 2.6$ points, $p<.01)$ and quartile 4 $(13.9 \pm 2.4$ points), and also that students from the quartile group 2 had lower average school grades $(p<.01)$ than students from quartile 4.

The comparison between genders showed that boys ( $15.9 \pm 2.1$ points) had better PE grades than girls $(14.3 \pm 2.1$ points), $t(1607)=-15.2, p<.01$. Conversely, girls had better grades than boys ( $p$ $<.01)$ in Portuguese, Philosophy, Mathematics, Foreign Language, Biology/Geology and Psychology. In Physics/Chemistry, Geography and History, there was no statistical difference between gender. The average grade of girls (13.5 \pm 2.3 points) was statistically higher than of boys (13.2 \pm 2.3 points), $t(1770)=5.6, p<.01$.

In Table 2 we indicate the summative assessment parameters of the eleven schools from which we have computed data analysis. In nine schools, the parameters include the proportion that each

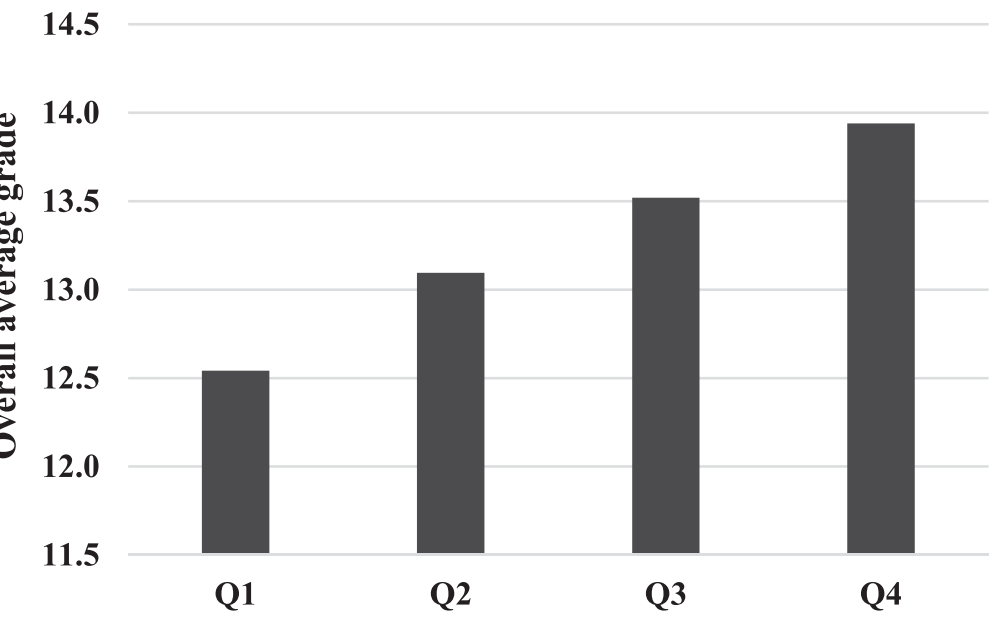

Figure 1. Overall average grade according to the students' Physical Education grade quartile.

Table 2. Summative assessment parameters in Physical Education.

\begin{tabular}{|c|c|c|c|c|}
\hline & Physical activities & Physical fitness & PE-related Knowledge & Participation and attitude \\
\hline School 1 & $90 \%$ & & & $10 \%$ \\
\hline School 2 & $55 \%$ & $20 \%$ & $20 \%$ & $5 \%$ \\
\hline School 3 & $70 \%$ & $10 \%$ & $10 \%$ & $10 \%$ \\
\hline School 4 & $75 \%$ & & $15 \%$ & $10 \%$ \\
\hline School 5 & $50 \%$ & $20 \%$ & $10 \%$ & $20 \%$ \\
\hline School 6 & $65 \%$ & $15 \%$ & $15 \%$ & $5 \%$ \\
\hline School 7 & $60 \%$ & $30 \%$ & $10 \%$ & - \\
\hline School 8 & $70 \%$ & & $10 \%$ & $20 \%$ \\
\hline School 9 & $55 \%$ & $15 \%$ & $15 \%$ & $15 \%$ \\
\hline $\begin{array}{l}\text { School } 10 \\
\text { School } 11\end{array}$ & \multicolumn{3}{|c|}{$\begin{array}{l}\text { There is not a proportion for each domain. First, students' performance in } \\
\text { physical activities is classified within } 5 \text { intervals (e.g. } 1-4,5-9,10-13,14- \\
17 \text { and } 18-20 \text { point); secondly, their performance in 'physical fitness' and } \\
\text { 'PE-related knowledge' is considered to determine a final grade within } \\
\text { that range }\end{array}$} & - \\
\hline
\end{tabular}

Note: PE, Physical Education. 
specific domain (physical activities, physical fitness, PE-related knowledge and participation/attitude) represents in the computation of the students' grades. In these schools, physical performance (physical activities and physical fitness) are most valued (70-90\% of the final grade) and only a relatively small proportion (5-20\%) is allocated to the PE-related knowledge or to the socio-affective domain (i.e. attitude, effort and participation). Two schools choose not to value the learning domains by percentage, but according to the description it is evident that the physical activities area is the most considered, and 'physical fitness' and 'PE-related knowledge' are used essentially for final grade adjustments. Three schools do not include explicitly the socio-affective domain in their assessment parameters; probably, in these schools such type of competences is considered inherent to the students' performance on the other learning domains. For other school subjects, specific abilities and knowledge represented $90-95 \%$ of the assessment and the remaining 5-10\% was constituted by social-affective competencies.

\section{Discussion}

This is one of the first studies that looked carefully at the PE grades in secondary schools, using a large sample of students. Overall, the results showed that the prevalence of negative grades in PE is residual, that $\mathrm{PE}$ grades are relatively higher than the grades in the most of other school subjects, and that PE and other school subject grades are positively associated. Also, the results point out that girls have lower PE grades than boys. The schools' summative assessment parameters value much more physical activities than physical fitness, knowledge and attitudinal elements.

One of the major research questions of this study was to understand the current level of achievement in Portuguese secondary school PE. The results showed that they are very satisfactory as the PE average grade was close to 15 points, and the number of students with a negative score was residual. Moreover, for most Portuguese students the PE grades raise their overall grade point average, which means that their average school grade is higher when the PE grade is included. Overall, the results are encouraging, suggesting that the Portuguese PE is contributing positively to the students' physical literacy during their school years. This is particularly important, considering that in Portugal the sport participation is relatively low outside school (Marques, Ekelund, and Sardinha 2016), and $\mathrm{PE}$ is probably the only period during the week in which a significant number of students engage in physical activities.

Although this study was not designed to reveal the reasons beyond the good level of students' success found in PE, it seems reasonable to point some hypothesis. In Portugal, for about 20 years there is a robust national PE programme that, among other things, provides information on PE goals, curriculum organization and assessment methods, which facilitates and orientates the teaching practices and the PE organization in different schools (Jacinto et al. 2001a, 2001b; Ministério da Educação 1998). The first five or six weeks of each school year constitutes a specific unit of learning where the students have the opportunity of practicing most of the physical activities that will be developed during the school year. In this phase, called initial assessment, the teacher collects important information on the students learning level. The pedagogical decisions on issues like the number of classes dedicated to each content, the formation of subgroups of students in some classes and the general conditions of practice are therefore based in the initial formative assessment.

There are another two aspects that may have contributed to the students' positive grades in PE. If, as expected, the schools follow the recommendations of the national PE programme, then the students' grades resulted from their summative assessment in some of the physical activities where they were more skilful and, in the 11th and 12th grades, the students selected some of the physical activities that were developed during the school year. This type of measures seems meritorious by giving students opportunities for success. Allowing students to choose some of the PE contents (especially, sport activities) in which they would like to increase their competence, is a good strategy for enhancing intrinsic motivation (e.g. enjoyment, perceived competence) (Ward et al. 2008; Prusak et al. 2004; Hamari et al. 2017) and it will be also reflected 
in high PE performance. It has been showed that students with higher levels of intrinsic motivation have higher PE grades (Barkoukis et al.2014), and that students with better PE achievement will probably be more physically active (Engström 2008; Sallis et al. 2012) and have a better health status as adults (Timpka et al. 2012).

One of our research questions was if PE grades are related to other school subjects' grades. The analysis of the school grades in relation to the PE grade quartiles showed an evident increase in academic performance from quartile 1 to quartile 4 . The results confirmed that the students with worse $\mathrm{PE}$ grades (quartiles 1 and 2) have worse academic grades than those in the higher PE grade quartile. Thus, in general, the students with higher results in PE also perform well in other school subjects and those with low results in PE also perform poorly in other school subjects. We examined further the association between PE achievement and academic achievement using correlation analysis and found that achievement in PE is positively associated with that of other curricular school-subjects. This finding is particularly relevant, considering the ongoing debate in Portugal about the recent government decision of reintroducing the $\mathrm{PE}$ grade as part of the secondary school aggregate grade used for the application to all courses at higher education level. One should note that studies over the past few decades have shown several interconnections between the cognitive and motor domains. This includes evidence that deficits in motor development typically co-occur with specific cognitive deficits (and vice versa), or that motor tasks share some of the same brain structure and circuits as cognitive ones (Diamond 2000; Piek, Pitcher, and Hay 1999). Recent studies have also reported that motor skills are associated with executive function and academic performance in children and adolescents (Aadland et al. 2017; Fernandes et al. 2016). Other studies have provided evidence that physical fitness, especially aerobic fitness, is positively associated with cognitive functioning (Donnelly et al. 2016) and academic achievement (Sallis et al. 1999).

It is important to highlight that the results of our study also showed that the level of association between the grades of the other school subject areas is much higher than that between PE and the other school subjects. Few studies performed this type of analysis. A recent study in Sweden (with students who fail to achieve grades to move on to upper secondary school) reported comparable correlation values ( $r$ 's $=.15$ to .37 ) between the grades in 'PE and health' and grades in Swedish, Mathematics, English (Ericsson and Cederberg 2015). We have also found a study that looked specifically at the contribution of physical activity and PE time for the grade point average and reported relatively small effects (Trudeau and Shephard 2008). The lower association found in the present study between PE grades and grades in other domains of the curriculum, than between the latter, is probably due to the basic abilities that underlie the level of achievement in each school subject. In the PE curriculum, motor-related learning and physical fitness are central elements wherein most of the other secondary school subjects there is a pervasiveness of cognitive-related competences. The results of the present study could be understood at the light of the framework provided by the multiple intelligence theory (Gardner 1999), which proposes the existence of several types of intelligence, been the bodily-kinesthetic probably the most directly related with PE achievement. In line with this idea, a previous study showed that there seems to be a general factor common to tests assessing purely cognitive abilities (e.g. Linguistic, Logical/Mathematical) but not for tests of other abilities, especially the bodily-kinesthetic (Visser, Ashton, and Vernon 2006). One should note that the fact that some school subjects (as PE) depend on specific abilities, does not withdraw its importance in the school curriculum but, on the contrary, it allows the development of an eclectic curriculum. In this context, PE should be considered an important school-subject per se, targeting essential psychomotor and social-affective competences that could not be promoted by other areas of the school curriculum. Such a point of view is distinct from the generalized school culture which values areas more dependent on cognitive knowledge (Bailey 2018). Unfortunately, such view has led to the reduction of the amount of school PE in some countries with the argument that by giving extra time to 'academic' school subjects one would raise students' performance (UNESCO 2014). As a fact, empirical evidence shows that the reduction or elimination of PE is not related to higher academic achievement, but, on the contrary, PE or school-based physical activity is 
positively associated with academic performance (Hillman, Erickson, and Kramer 2008; Marques et al. 2017).

One of the main research questions of this study was to find out if boys and girls have different PE grades. Our results showed that boys had higher PE grades than girls, but the inverse was found for the grades in the other school subjects. The mean difference between boys and girls was markedly higher for the PE grades (1.5 points) than for the overall school grade ( 0.3 points). Thus, although girls tend to excel boys in school subjects which depend more on cognitive-related competences, boys surpass girls in PE where motor-related skills and physical fitness are central elements. These differences in PE should not be entirely expected in the Portuguese secondary school if one considers that the PE programme posits that in the 11th and 12th years students might select some of the physical activities to be developed during the school year (probably, they tend to choose the physical activities where they feel more competent). One should note, however, that, to our knowledge, there is no information available on the level of implementation of this PE programme recommendation in Portuguese schools.

The disparity found in the current study in PE grades between genders (also found in other countries; Ericsson and Cederberg 2015; Aune et al. 2017) should serve as an alert and prompt researchers and education authorities to look for the reasons why girls have lower achievement scores in PE and to find measures to revert the situation. Previous studies have already shown that the overall quality of fundamental motor skills is persuasively inferior in girls from the preschool to the high-school years (Barnett et al. 2010; Spessato et al. 2013). Considering that our results showed that physical performance is the most valued domain in the schools for PE grading, it seems logical to assume that, in general, the girls in the present study have lower performance in contents like sports or physical fitness. How can PE and school contribute to changing such discrepancies between genders? One of the strategies could be the reinforcement of attractive school sports programmes since the early years and of developmental programmes focused on motor competence. A recent study showed that well-designed interventions in preschool could enhance preschool-age girls' ball skill performance (Veldman et al. 2017), which adds to other comparable studies that also found positive improvements in motor competence for both boys and girls (Zask et al. 2012). Some other possible strategies for enhancing the interest and participation of girls in PE include noncompetitive environments, activities that are fun for different skill levels (and interests), and girl-only classes (Barr-Anderson et al. 2008). Considering that girls are often marginalized in coeducational classes, it was also suggested that a good strategy is to implement multiple competitions in PE, that is, girls' competition, boys' competition and mixed competition (Siedentop, Hastie, and Van der Mars 2011). Interestingly, in Finland, where single-gender classes are the norm in grades 5-9, the average PE grade for students in the 9th academic year is very similar between boys and girls (Yli-Piipari 2014)

Finally, the last research question of this study was to find out the summative PE assessment parameters used in schools. Nine of the eleven schools that participate, establish a proportion per domain for calculating the final PE grade: In these schools, physical performance (physical activities and physical fitness) represent $70-90 \%$ of the students' grade, and a smaller percentage is allocated to other domains, namely to the socio-affective domain (0-20\%) and PE-related knowledge (10-20\%). Also, it is interesting to note that the number of summative assessment parameters is higher in PE than in the other school subjects, as well as the range of percentage given to the criterion 'participation and attitude' (it represents only $5-10 \%$ of the grade in other school subjects).

It is important to highlight that the Portuguese PE summative assessment norms (included in the national PE programme) do not propose a separate grade for socio-affective elements as they are considered intertwined with the attainment of skills in the other domains. For instance, the cooperation with colleagues, the acceptance of suggestions by others, and the respect by social rules are viewed in the PE programme as values embedded in the physical activities contents and goals. Still, although most schools that participated in the current study use a separate grade for socio-affective elements, some level of standardization can be observed in the results. Hence, in 
all schools, the students' grades in secondary PE reflect, above all, their physical competence (especially, mastery of skills in physical activities), and the knowledge of PE content and socio-affective domains have much more modest contributions to the students' final grade. Overall, this is a positive finding, as it seems that one of the reasons why PE is not taken so seriously by the educational community as other school subjects, is the importance that traditionally has been attributed to the assessment of elements as effort, attendance, participation and attitude (Baghurst 2014; Collier 2011). As Collier puts it, a positive status of PE is not compatible with a situation where grading is determined by variables as attendance, showering and good behaviour. Although important, such type of variables are prerequisites for learning and not learning targets (Melograno 2007). Considering all this, it seems desirable that in the future all Portuguese schools follow the PE programme guidelines, reflecting core socio-affective values such as cooperation and respect by the rules in the physical performance domain and report separately (without direct consequences in grading) elements like attendance, attire, effort and participation, like it has been previously proposed (Baghurst 2014; Collier 2011).

This study has some limitations. First of all, we collect data on the results that students achieved in high school PE and on the general assessment parameters used in the schools, but we did not examine in depth what are the actual assessment practices. We now know the weight that each specific types of competencies have in the students' grades, confirming, for instance, that motor competencies and physical fitness are highly considered, and that subjective attitudinal and behaviour competencies have limited relevance. Nevertheless, it is necessary to examine to a much deeper level the 'theory and practice' of PE assessment in Portugal, including aspects as how students are involved in assessment and grading, what are the actual connections between summative and formative assessment, or the level of teachers' compliance with the national PE programme. Also, this study was limited to one of the five educational administrative regions of Portugal, and a considerable number of secondary schools that were contacted did not participate. Nevertheless, the number of participants was relatively large, and the study provides new and relevant information on the students' performance in the secondary school. Finally, we did not collect information that could be related to the level of achievement in PE, including the students' participation in sports activities and their physical activity patterns. Importantly, the correlation nature of this study makes it impossible to establish causal relationships, namely between the level of achievement in PE and academic achievement. Finally, we hope that the present research incites other investigators to extend the current knowledge on the multiple aspects of PE assessment in Portugal and other countries.

\section{Conclusion}

First of all, this study provided information about the Portuguese high school assessment in PE, showing that the students' level of achievement is very satisfactory, as only $\sim 1 \%$ of students with a final PE grade (at the end of the third school period) had a negative performance ( $<10$ points) and as PE grades are significantly higher than most grades on the other school subjects. It is important to explore in the future the reasons underlying this apparent success of PE, including the relevance of the national PE programme and of the instructional models adopted by PE teachers.

This study also found that PE grades are positively associated with the grades of almost all school subjects, but that the level of association between the grades in the other school subjects is markedly higher. This indicates that PE involves specific competencies that do not necessarily overlap with those related to other school subjects. Considering the current interest in the education-related literature on the relationship between motor and cognitive competencies (e.g. Fernandes et al. 2016), such positive association of $\mathrm{PE}$ grades with academic achievement could have a positive impact in the PE status. For instance, it enters somewhat in a collision course with the unfortunate idea that by reducing the time allocated to $\mathrm{PE}$ and by giving extra time to 'academic' school subjects it would raise overall students' performance. 
Importantly, the results showed that boys have better grades in PE than girls, but the opposite occurs in most of the other school subjects. It is imperative to identify the reasons for these performance differences between genders in order to plan appropriate measures. Based in previous research (e.g. Barr-Anderson et al. 2008; Veldman et al. 2017), some hypothesis to reverse such discrepancies and for promoting participation and enjoyment of girls in PE were discussed in this article. They included offering activities that are fun for girls with different skill levels and interests, skill-enhancing programmes to increase self-efficacy, girl-only classes (or girl-only groups in some activities) and noncompetitive environments.

It is largely accepted that for a quality PE, summative assessment criteria should not be based on effort and participation but in the mastery of the skills and goals presented in the national standards. The information collected about the school's assessment parameters points out that motor skills related to physical activities are the primary criteria for grading in PE. This constitutes a positive outcome, as grounding grades predominantly on subjective attitudinal measures could undermine $\mathrm{PE}$ and threaten its credibility as a legitimate standards-based discipline (Sundaresan, Dashoush, and Shangraw 2017).

In summary, the information collected in the present study could be useful at both the educational system and the school levels, providing valuable feedback on the current level of PE performance in Portuguese secondary schools, which can inform pedagogical practices and policy measures. It could also set the basis for future in-depth examinations into the PE assessment process in the country. Nevertheless, it provided only a brief glance into some aspects of the assessment of PE in Portugal, and is it is desirable that future investigations examine relevant issues like the actual relationship between summative and formative assessment, the level of alignment between assessment practices and the course goals of the national PE programme, or if students are well informed about what is considered for calculating their grades and the rationale behind it.

\section{Acknowledgements}

We would like to thank all the schools that agreed to participate in this study.

\section{Disclosure statement}

No potential conflict of interest was reported by the authors.

\section{ORCID}

José Marmeleira (1D) http://orcid.org/0000-0002-5534-9600

Hugo Folgado (D) http://orcid.org/0000-0002-9432-1950

Ismael Martínez Guardado (D) http://orcid.org/0000-0002-3557-9767

Nuno Batalha (D) http://orcid.org/0000-0001-8533-7144

\section{References}

Aadland, K. N., V. F. Moe, E. Aadland, S. A. Anderssen, G. K. Resaland, and Y. Ommundsen. 2017. "Relationships between Physical Activity, Sedentary Time, Aerobic Fitness, Motor Skills and Executive Function and Academic Performance in Children." Mental Health and Physical Activity 12: 10-18. doi:10.1016/j.mhpa.2017.01.001.

Aune, T. K., A. V. Pedersen, R. P. Ingvaldsen, and T. Dalen. 2017. "Relative Age Effect and Gender Differences in Physical Education Attainment in Norwegian Schoolchildren.” Scandinavian Journal of Educational Research 61 (3): 369-375. doi:10.1080/00313831.2016.1148073.

Baghurst, T. 2014. “Assessment of Effort and Participation in Physical Education.” Physical Educator 71 (3): $505-513$.

Bailey, R. 2018. “Sport, Physical Education and Educational Worth.” Educational Review 70 (1): 51-66. doi:10.1080/ 00131911.2018.1403208.

Barkoukis, V., I. Taylor, J. Chanal, and N. Ntoumanis. 2014. “The Relation between Student Motivation and Student Grades in Physical Education: A 3-Year Investigation.” Scandinavian Journal of Medicine \& Science in Sports 24 (5): e406-ee14. doi:10.1111/sms.12174. 
Barnett, L. M., E. van Beurden, P. J. Morgan, L. O. Brooks, and J. R. Beard. 2010. “Gender Differences in Motor Skill Proficiency from Childhood to Adolescence.” Research Quarterly for Exercise and Sport 81 (2): 162-170. doi:10. 1080/02701367.2010.10599663.

Barr-Anderson, D. J., D. Neumark-Sztainer, K. H. Schmitz, D. S. Ward, T. L. Conway, C. Pratt, C. D. Baggett, L. Lytle, and R. R. Pate. 2008. "But I Like PE: Factors Associated With Enjoyment of Physical Education Class in Middle School Girls.” Research Quarterly for Exercise and Sport 79 (1): 18-27. doi:10.1080/02701367.2008.10599456.

Borghouts, L. B., M. Slingerland, and L. Haerens. 2017. "Assessment Quality and Practices in Secondary PE in the Netherlands." Physical Education and Sport Pedagogy 22 (5): 473-489. doi:10.1080/17408989.2016.1241226.

Coe, D. P., J. M. Pivarnik, C. J. Womack, M. J. Reeves, and R. M. Malina. 2006. "Effect of Physical Education and Activity Levels on Academic Achievement in Children." Medicine and Science in Sports and Exercise 38 (8): 1515-1519. doi:10.1249/01.mss.0000227537.13175.1b.

Cohen, J. 1987. Statistical Power Analysis for the Behavioral Sciences. Revised edition. Hillsdale, NJ: Lawrence Erlbaum Associates.

Collier, D. 2011. "Increasing the Value of Physical Education: The Role of Assessment." Journal of Physical Education, Recreation \& Dance 82 (7): 38-41.

Dexter, T. 1999. "Relationships between Sport Knowledge, Sport Performance and Academic Ability: Empirical Evidence from GCSE Physical Education.” Journal of Sports Sciences 17 (4): 283-295. doi:10.1080/ 026404199366000.

Diamond, A. 2000. "Close Interrelation of Motor Development and Cognitive Development and of the Cerebellum and Prefrontal Cortex." Child Development 71 (1): 44-56. doi:10.1111/1467-8624.00117.

Direção Geral da Educação. n.d. “Aprendizagens essenciais - 1. ${ }^{\circ}$ ciclo do ensino básico, educação física.” http://www. dge.mec.pt/educacao-fisica.

Donnelly, J. E., C. H. Hillman, D. Castelli, J. L. Etnier, S. Lee, P. Tomporowski, K. Lambourne, and A. N. Szabo-Reed. 2016. "Physical Activity, Fitness, Cognitive Function, and Academic Achievement in Children: A Systematic Review." Medicine and Science in Sports and Exercise 48 (6): 1197-1222. doi:10.1249/MSS.0000000000000901.

Engström, L.-M. 2008. "Who Is Physically Active? Cultural Capital and Sports Participation from Adolescence to Middle Age-A 38-Year Follow-Up Study." Physical Education and Sport Pedagogy 13 (4): 319-343. doi:10. $1080 / 17408980802400510$.

Ericsson, I. 2008. "Motor Skills, Attention and Academic Achievements. An Intervention Study in School Years 1-3." British Educational Research Journal 34 (3): 301-313. doi:10.1080/01411920701609299.

Ericsson, I., and M. Cederberg. 2015. "Physical Activity and School Performance: A Survey among Students Not Qualified for Upper Secondary School.” Physical Education and Sport Pedagogy 20 (1): 45-66. doi:10.1080/ 17408989.2013 .788146$.

Esteban-Cornejo, I., C. M. Tejero-Gonzalez, J. F. Sallis, and O. L. Veiga. 2015. "Physical Activity and Cognition in Adolescents: A Systematic Review." Journal of Science and Medicine in Sport 18 (5): 534-539. doi:10.1016/j. jsams.2014.07.007.

Fairclough, S. 2003. "Physical Activity, Perceived Competence and Enjoyment during High School Physical Education." European Journal of Physical Education 8 (1): 5-18. doi:10.1080/1740898030080102.

Fairclough, S., and G. Stratton. 2005. “Physical Education Makes You Fit and Healthy'. Physical Education's Contribution to Young People's Physical Activity Levels.” Health Education Research 20 (1): 14-23. doi:10.1093/ her/cyg101.

Fernandes, V. R., M. L. S. Ribeiro, T. Melo, P. de Tarso Maciel-Pinheiro, T. T. Guimarães, N. B. Araújo, S. Ribeiro, and A. C. Deslandes. 2016. "Motor Coordination Correlates with Academic Achievement and Cognitive Function in Children.” Frontiers in Psychology 7: 318. doi:10.3389/fpsyg.2016.00318.

Gardner, H. E. 1999. Intelligence Reframed: Multiple Intelligences for the 21st Century. New York: Basic Books.

Hamari, L., O. J. Heinonen, M. Aromaa, R. Asanti, L. Koivusilta, P. Koski, C. Laaksonen, et al. 2017. "Association of Self-Perceived Physical Competence and Leisure-Time Physical Activity in Childhood-A Follow-Up Study.” Journal of School Health 87 (4): 236-243. doi:10.1111/josh.12490.

Hardy, L. L., T. Reinten-Reynolds, P. Espinel, A. Zask, and A. D. Okely. 2012. "Prevalence and Correlates of Low Fundamental Movement Skill Competency in Children.” Pediatrics 130 (2): e390-e398. doi:10.1542/peds.20120345 .

Harlen, W. 2012. “On the Relationship Between Assessment for Formative and Summative Purposes.” In Assessment and Learning, edited by J. Gardner, 87-102. London: Sage publications.

Hillman, C. H., K. I. Erickson, and A. F. Kramer. 2008. "Be Smart, Exercise Your Heart: Exercise Effects on Brain and Cognition.” Nature Reviews Neuroscience 9: 58-65. doi:10.1038/nrn2298.

Jacinto, J., L. Carvalho, J. Comédias, and J. Mira. 2001a. "Programa de Educação Física do $3^{\circ}$ ciclo do Ensino Básico." Lisboa: Ministério da Educação, Departamento do Ensino Básico.

Jacinto, J., L. Carvalho, J. Comédias, and J. Mira. 2001b. "Programa de Educação Física para o Ensino Secundário." Lisboa: Ministério da Educação, Departamento do Ensino Secundário.

Lau, A. M. S. 2016. “'Formative Good, Summative Bad?' - A Review of the Dichotomy in Assessment Literature.” Journal of Further and Higher Education 40 (4): 509-525. doi:10.1080/0309877X.2014.984600. 
Leirhaug, P. E., and C. Annerstedt. 2016. "Assessing with New Eyes? Assessment for Learning in Norwegian Physical Education.” Physical Education and Sport Pedagogy 21 (6): 616-631. doi:10.1080/17408989.2015.1095871.

MacPhail, A. 2015. "International Perspectives on the Implementation of Standards." In Standards Based Physical Education Curriculum Development, edited by J. Lund, and D. Tannehill, 21-36. Burlington, MA: Jones \& Bartlett Learning.

Marmeleira, J. 2013. “An Examination of the Mechanisms Underlying the Effects of Physical Activity on Brain and Cognition.” European Review of Aging and Physical Activity 10 (2): 83-94. doi:10.1007/s11556-012-0105-5.

Marmeleira, J., N. Aldeias, and P. Graça. 2012. "Physical Activity Levels in Portuguese High School Physical Education.” European Physical Education Review 18 (2): 191-204. doi:10.1177/1356336X12440022.

Marques, A., U. Ekelund, and L. B. Sardinha. 2016. "Associations between Organized Sports Participation and Objectively Measured Physical Activity, Sedentary Time and Weight Status in Youth." Journal of Science and Medicine in Sport 19 (2): 154-157. doi:10.1016/j.jsams.2015.02.007.

Marques, A., F. Gómez, J. Martins, R. Catunda, and H. Sarmento. 2017. “Association between Physical Education, School-Based Physical Activity, and Academic Performance: A Systematic Review.” Retos 31: 316-320.

Mayorga-Vega, D., A. Martínez-Baena, and J. Viciana. 2018. "Does School Physical Education Really Contribute to Accelerometer-Measured Daily Physical Activity and Non Sedentary Behaviour in High School Students?” Journal of Sports Sciences 36 (17): 1913-1922. doi:10.1080/02640414.2018.1425967.

Melograno, V. J. 2007. “Grading and Report Cards for Standards-Based Physical Education.” Journal of Physical Education, Recreation \& Dance 78 (6): 45-53. doi:10.1080/07303084.2007.10598041.

Ministério da Educação. 1998. “Programa de Educação Física do $2^{\circ}$ Ciclo (Volumes I e II).” Lisboa: Ministério da Educação, Departamento da Educação Básica.

Newton, P. E. 2007. "Clarifying the Purposes of Educational Assessment." Assessment in Education: Principles, Policy \& Practice 14 (2): 149-170. doi:10.1080/09695940701478321.

Penny, L. 2013. "Ritual Associated with Participation in Physical Education: The Power of Excuse Notes." European Physical Education Review 20 (1): 120-139. doi:10.1177/1356336X13496005.

Piek, J. P., T. M. Pitcher, and D. A. Hay. 1999. "Motor Coordination and Kinaesthesis in Boys with Attention DeficitHyperactivity Disorder.” Developmental Medicine \& Child Neurology 41 (3): 159-165.

Prusak, K. A., D. C. Treasure, P. W. Darst, and R. P. Pangrazi. 2004. "The Effects of Choice on the Motivation of Adolescent Girls in Physical Education.” Journal of Teaching in Physical Education 23 (1): 19-29. doi:10.1123/ jtpe.23.1.19.

Rasberry, C. N., S. M. Lee, L. Robin, B. A. Laris, L. A. Russell, K. K. Coyle, and A. J. Nihiser. 2011. “The Association between School-Based Physical Activity, Including Physical Education, and Academic Performance: A Systematic Review of the Literature." Preventive Medicine 52: S10-S20. doi:10.1016/j.ypmed.2011.01.027.

Redelius, K., and P. J. Hay. 2012. "Student Views on Criterion-Referenced Assessment and Grading in Swedish Physical Education." Physical Education and Sport Pedagogy 17 (2): 211-225. doi:10.1080/17408989.2010.548064.

Richardson, K. P. 2011. "Physical Education Teacher Education: Creating a Foundation to Increase the Status of Physical Education in Schools." Journal of Physical Education, Recreation \& Dance 82 (7): 45-56.

Sallis, J. F., T. L. McKenzie, M. W. Beets, A. Beighle, H. Erwin, and S. Lee. 2012. "Physical Education's Role in Public Health.” Research Quarterly for Exercise and Sport 83 (2): 125-135. doi:10.1080/02701367.2012.10599842.

Sallis, J. F., T. L. McKenzie, B. Kolody, M. Lewis, S. Marshall, and P. Rosengard. 1999. "Effects of Health-Related Physical Education on Academic Achievement: Project SPARK." Research Quarterly for Exercise and Sport 70 (2): 127-134. doi:10.1080/02701367.1999.10608030.

Sheehy, D. A. 2011. “Addressing Parents' Perceptions in the Marginalization of Physical Education." Journal of Physical Education, Recreation \& Dance 82 (7): 42-56. doi:10.1080/07303084.2011.10598657.

Siedentop, D., P. A. Hastie, and H. Van der Mars. 2011. Complete Guide to Sport Education. Champaign, IL: Human Kinetics.

Silva, I., L. Marques, L. Mata, and M. Rosa. 2016. “Orientações curriculares para a educação pré-escolar.” Lisboa: Ministério da Educação/Direção-geral da Educação.

Smith, N. J., M. A. F. Lounsbery, and T. L. McKenzie. 2014. "Physical Activity in High School Physical Education: Impact of Lesson Context and Class Gender Composition." Journal of Physical Activity and Health 11 (1): 127135. doi:10.1123/jpah.2011-0334.

Spessato, B. C., C. Gabbard, N. Valentini, and M. Rudisill. 2013. “Gender Differences in Brazilian Children's Fundamental Movement Skill Performance.” Early Child Development and Care 183 (7): 916-923. doi:10.1080/ 03004430.2012 .689761$.

Stiggins, R. 2007. “Assessment through the Student's Eyes.” Educational Leadership 64 (8): 22-26.

Sundaresan, N., N. Dashoush, and R. Shangraw. 2017. “Now That We're 'Well Rounded,' Let's Commit to Quality Physical Education Assessment." Journal of Physical Education, Recreation \& Dance 88 (8): 35-38. doi:10.1080/ 07303084.2017.1356770.

Taras, M. 2005. “Assessment - Summative and Formative - Some Theoretical Reflections.” British Journal of Educational Studies 53 (4): 466-478. doi:10.1111/j.1467-8527.2005.00307.x. 
Telford, R. M., R. D. Telford, T. Cochrane, R. B. Cunningham, L. S. Olive, and R. Davey. 2016. "The Influence of Sport Club Participation on Physical Activity, Fitness and Body Fat During Childhood and Adolescence: The LOOK Longitudinal Study." Journal of Science and Medicine in Sport 19 (5): 400-406. doi:10.1016/j.jsams.2015.04.008.

Timo, J., Y.-P. Sami, W. Anthony, and L. Jarmo. 2016. "Perceived Physical Competence towards Physical Activity, and Motivation and Enjoyment in Physical Education as Longitudinal Predictors of Adolescents' Self-Reported Physical Activity." Journal of Science and Medicine in Sport 19 (9): 750-754. doi:10.1016/j.jsams.2015.11.003.

Timpka, S., I. F. Petersson, R. Rylance, L. Kedza, and M. Englund. 2012. "Performance in Physical Education and Health Impairment 30 Years Later-A Community Based Cohort Study." PLoS ONE 7 (4): e35718. doi:10.1371/ journal.pone.0035718.

Trudeau, F., and R. J. Shephard. 2008. "Physical Education, School Physical Activity, School Sports and Academic Performance." International Journal of Behavioral Nutrition and Physical Activity 5 (1): 10. doi:10.1186/14795868-5-10.

UNESCO. 2014. "World-Wide Survey of School Physical Education. Final Report 2013." Paris: United Nations Educational, Scientific and Cultural Organization.

Vandorpe, B., J. Vandendriessche, R. Vaeyens, J. Pion, S. Matthys, J. Lefevre, R. Philippaerts, and M. Lenoir. 2012. "Relationship between Sports Participation and the Level of Motor Coordination in Childhood: A Longitudinal Approach." Journal of Science and Medicine in Sport 15 (3): 220-225. doi:10.1016/j.jsams.2011.09.006.

Veldman, S. L. C., K. K. Palmer, A. D. Okely, and L. E. Robinson. 2017. "Promoting Ball Skills in Preschool-Age Girls." Journal of Science and Medicine in Sport 20 (1): 50-54. doi:10.1016/j.jsams.2016.04.009.

Vilhjalmsson, R., and G. Kristjansdottir. 2003. "Gender Differences in Physical Activity in Older Children and Adolescents: The Central Role of Organized Sport.” Social Science \& Medicine 56 (2): 363-374. doi:10.1016/ S0277-9536(02)00042-4.

Visser, B. A., M. C. Ashton, and P. A. Vernon. 2006. "Beyond g: Putting Multiple Intelligences Theory to the Test." Intelligence 34 (5): 487-502. doi:10.1016/j.intell.2006.02.004.

Ward, J., C. Wilkinson, S. V. Graser, and K. A. Prusak. 2008. "Effects of Choice on Student Motivation and Physical Activity Behavior in Physical Education." Journal of Teaching in Physical Education 27 (3): 385-398. doi:10.1123/ jtpe.27.3.385.

Yli-Piipari, S. 2014. "Physical Education Curriculum Reform in Finland." Quest 66 (4): 468-484. doi:10.1080/ 00336297.2014.948688.

Zask, A., L. Barnett, L. Ros, L. Brooks, M. Molyneux, D. Hughes, J. Adams, and J. Salmon. 2012. "Does a Movement Skill Intervention in Preschools Result in Movement Skill and Physical Activity Outcomes Three Years Later?" Journal of Science and Medicine in Sport 15: S61. doi:10.1016/j.jsams.2012.11.148. 